\title{
Long-Term Improvement of Chronic Low-Grade Inflammation After Bariatric Surgery
}

\author{
Anne Lautenbach ${ }^{1}$ (D) $\cdot$ Fabian Stoll ${ }^{1}$ - Oliver Mann ${ }^{2} \cdot$ Philipp Busch $^{2} \cdot$ Tobias B. Huber $^{1} \cdot$ Heike Kielstein $^{3} \cdot$ Ina Bähr $^{3}$. \\ Jens Aberle ${ }^{1}$
}

Received: 7 December 2020 / Revised: 23 February 2021 / Accepted: 23 February 2021 / Published online: 5 March 2021

(C) The Author(s) 2021

\begin{abstract}
Purpose Bariatric surgery (BS) was shown to improve inflammatory markers in previous short-term follow-up studies. The aim of the present study was to assess the long-term effects of BS on chronic low-grade inflammation markers related to severe obesity. Moreover, the meaning of the type of BS procedure as well as the remission of type 2 diabetes (T2D) for inflammatory status up to 4 years after BS was analyzed.

Materials and Methods In a retrospective cohort study including 163 patients at baseline, inflammatory and metabolic parameters were assessed at 4 time points: before surgery (baseline), 6 months after surgery (visit 1), 2 years after surgery (visit 2), and 4 years after surgery (visit 3). Univariate regression analysis was used to identify variables that were thought to determine change in inflammatory parameters.

Results CRP, hs-CRP, leucocytes, and ferritin significantly declined in the mid- and long-term according to the U-shaped curve of weight loss $(p<0.001)$. Change in body mass index (BMI) at long-time follow-up showed a significant linear effect on change in leucocytes $(B=0.082 ; p<0.001)$ and change in hs-CRP $(B=0.03 ; p<0.05)$. There was a strong, positive correlation between T2D and hs-CRP at visit $2\left(r_{s}=0.195 ; p<0.05\right)$ and visit $3\left(r_{s}=0.36 ; p=0.001\right)$. With regard to type of surgery and gender, there were no significant differences in inflammatory parameters.

Conclusion BS is able to reduce obesity-related chronic low-grade inflammation up to 4 years after surgical intervention. The improvement in metaflammation is related to the change in BMI and remission of T2D in the long-term.
\end{abstract}

Keywords Bariatric surgery $\cdot$ Inflammation $\cdot$ High-sensitive CRP $\cdot$ Obesity $\cdot$ Weight loss

\section{Introduction}

Obesity is associated with metaflammation, a metabolically triggered systemic chronic low-grade inflammation

Anne Lautenbach

a.lautenbach@uke.de

Fabian Stoll

fabian-david.stoll@stud.uke.uni-hamburg.de

Oliver Mann

omann@uke.de

Philipp Busch

pbusch@uke.de

Tobias B. Huber

t.huber@uke.de

Heike Kielstein

Heike.Kielstein@uk-halle.de characterized by an augmented release of pro-inflammatory factors caused by the increased number of adipocytes and immune cells in adipose tissue [1]. Previous data demonstrated that the inflammatory condition in obesity contributes to

Ina Bähr

ina.baehr@uk-halle.de

Jens Aberle

aberle@uke.de

1

III. Department of Medicine, University Medical Center Hamburg-Eppendorf, Martinistr. 52, 20246 Hamburg, Germany

2 Department of General, Visceral and Thoracic Surgery, University Medical Center Hamburg-Eppendorf, Hamburg, Germany

3 Institute of Anatomy and Cell Biology, Medical Faculty of Martin Luther University Halle-Wittenberg, Halle (Saale), Germany 
the metabolic syndrome and other obesity-associated pathophysiological outcomes [2].

The inflammatory status in individuals with obesity can be measured by quantification of several inflammatory markers, like pro-inflammatory cytokines (e.g., tumor-necrosis factor- $\alpha$ and interleukin-6), number of leucocytes, and several adipokines. In addition, increased serum concentrations of the acute-phase reactants C-reactive proteins (CRP) and highsensitivity CRP (hs-CRP) are commonly used to monitor inflammation and are strongly associated with metabolic syndrome, atherosclerotic cardiovascular disease, and T2D [3, 4]. Moreover, decreased levels of anti-inflammatory estrogens indicate inflammatory alterations in obesity [5].

Previous studies already demonstrated that loss of body weight and fat mass after bariatric surgery (BS) improves inflammatory parameters in patients with severe obesity [6-10]. However, in most of these studies inflammatory markers were analyzed after a follow-up duration up to 12 months after bariatric surgery, only 5 out of 116 studies had a follow-up period of more than 24 months according to a systematic review about the effect of BS on serum inflammatory markers of patients with obesity [11]. Moreover, only few data exist investigating the impact of surgery technique or gender on the postoperative inflammatory state. Therefore, the primary aim of the present study was to investigate changes of obesity-related inflammatory and metabolic parameters in male and female patients 6 month, 2 years, and 4 years after different bariatric procedures. Moreover, secondary aims were to examine whether the intensity of weight loss, the remission of T2D, and the type of surgery are associated with the grade of inflammation after BS.

\section{Materials and Methods}

\section{Study Population}

Male or female patients $\geq 18$ years who underwent either sleeve gastrectomy (SG) or Roux-en-Y gastric bypass (RYGB) according to the S3 Leitlinie (Guidelines) Chirurgie der Adipositas [12] were included in the analysis. Patients with second step procedures during follow-up were considered having SG $(n=6)$. Patients attended our obesity outpatient clinic between 2014 and 2020, which is certified as center of excellence for obesity and metabolic surgery by the European Accreditation Council for Bariatric Surgery. Exclusion criteria included incomplete records, history of acute inflammation (pulmonary, gastrointestinal, urogenital, cutaneous, or history of chronic autoinflammatory disease), and pregnancy. Of an initial population of 237 patients, 74 were excluded $(n=163)$.

\section{Study Design}

Follow-up data were retrospectively collected from 163 patients at baseline. To provide reasonable comparability between the cases, the available data were allocated 3 "visits" by time in relation to the procedure. In addition to baseline data $-5.43 \pm 4.17(m e a n \pm S D)$ months before surgery, data from visit $1(n=160)$ were analyzed 6 months after surgery, data from visit $2(n=128) 2$ years after surgery, and data from visit $3(n=75) 4$ years post-BS.

\section{Variables}

Data on height $(\mathrm{cm})$, weight $(\mathrm{kg})$, body mass index (BMI; $\mathrm{kg} /$ $\left.\mathrm{m}^{2}\right)$, gender, age, leucocytes $\left(10^{3} / \mu \mathrm{l}\right)$, CRP $(\mathrm{mg} / \mathrm{l})$, hs-CRP $(\mathrm{mg} / \mathrm{dl})$, hemoglobin $(\mathrm{g} / \mathrm{dl})$, transferrin $(\mathrm{g} / \mathrm{l})$, transferrin saturation $(\%)$, ferritin $(\mu \mathrm{g} / \mathrm{l})$, estradiol $(\mathrm{ng} / \mathrm{dl})$, aspartate aminotransferase (AST; U/l), alanine aminotransferase (ALT; U/l), gamma-glutamyl transpeptidase (GGT; U/l), triglycerides ( $\mathrm{mg} / \mathrm{dl}$ ), high-density lipoprotein cholesterol (HDL; mg/dl), low-density lipoprotein cholesterol (LDL; $\mathrm{mg} / \mathrm{dl}$ ), and $\mathrm{HbA1c}(\%)$ were analyzed at baseline and during follow-up. Excess weight loss (EWL) in \% was calculated by dividing the difference between initial BMI and final BMI by the difference between initial BMI and a target BMI of $25 \mathrm{~kg} / \mathrm{m}^{2}$. Optimal weight loss was defined as losing at least $50 \%$ of the excess weight during the first 2 years after the procedure $[13,14]$.

Additionally, the prevalence of T2D was assessed. T2D was assumed if the diagnosis was pre-existing or if patients required antidiabetic medication or if $\mathrm{HbAl} \mathrm{c}$ was above $6.5 \%$. Complete remission of T2D was defined as $\mathrm{HbA} 1 \mathrm{c} \leq 6.0 \%$ and no use of antidiabetic medication, partial remission of T2D was defined as $\mathrm{HbA} 1 \mathrm{c} \leq 6.5 \%$ and no use of antidiabetic medication [15]. Due to the low number of cases, patients with partial remission were considered having T2D.

\section{Statistical Analysis}

Independent variables were tested using Student's $t$-test with Levene's test for equality of variances. Normal distribution was tested with Shapiro-Wilk test.

Spearman's rank correlation was performed to assess the relationship between glycemic control and inflammatory parameters. Linear regression analysis was performed to identify independent variables that determined the change in inflammatory parameters at long-term follow-up. The values are expressed as mean $\pm \mathrm{SD}$. For all statistical tests, a $p<0.05$ was considered statistically significant. All analyses were conducted using SPSS software, version 27 for Windows, IBM, Germany. 


\section{Results}

\section{Demographic Data}

Baseline characteristics are presented in Table 1. Mean age was $41.3 \pm 11.6$ years, $75.4 \%$ of patients were female; $66.3 \%$ of patients underwent SG, and $33.7 \%$ underwent RYGB as initial weight loss procedure. Mean BMI was $51.63 \pm 8.02 \mathrm{~kg} /$ $\mathrm{m}^{2} ; 30.7 \%$ of patients were diagnosed with T2D.

\section{Weight Loss Outcomes}

At visit 1, there were steep reductions in body weight $(153.5 \pm 29.2$ versus $117.8 \pm 24.6 \mathrm{~kg} ; p<0.001)$ and BMI $\left(51.63 \pm 8.02\right.$ versus $\left.39.62 \pm 7.22 \mathrm{~kg} / \mathrm{m}^{2} ; p<0.001\right)$. Further reductions in body weight and BMI occurred at visit 2 $\left(104.0 \pm 26.1 \mathrm{~kg}, p<0.001 ; 35.20 \pm 7.99 \mathrm{~kg} / \mathrm{m}^{2}, p<0.001\right)$ and visit $3\left(108.8 \pm 31.9 \mathrm{~kg}, p<0.001 ; 36.49 \pm 9.67 \mathrm{~kg} / \mathrm{m}^{2}\right.$, $p<0.001)$ compared to baseline (Table 1 ). Weight regain at visit 3 was statistically not significant compared to visit $2(p=0.251) ; 65.6 \%$ of patients showed a sustained weight loss of greater than $50 \%$ EWL during the first 2 years after surgery.

\section{Leucocyte count, CRP, and hs-CRP}

Leucocyte count continuously dropped over the follow-up period ( $p<0.001$ for all visits; Table 1$)$. Weight loss was accompanied by a steep decline in mean CRP at visit 1 compared to baseline. Further reductions in mean CRP occurred at visit 2 and visit 3 , respectively ( $p<0.001$ for all visits). The slight increase in CRP at visit 3 was statistically not significant compared to visit $2(p=0.114)$.

Accordingly, hs-CRP decreased from baseline to visit 1. At visit 2 and visit 3 , a further decrease in hs-CRP was seen, respectively ( $p<0.001$ for all visits). The slight increase in hs-CRP at visit 3 was statistically not significant compared to visit $2(p=0.188)$.

At visit $1,56.9 \%$ of patients showed complete normalization of inflammatory markers (leucocytes and hs-CRP). At visit 2 and visit 3, the percentage increased to $85.2 \%$ and $84.0 \%$, respectively.

\section{Ferritin}

At visit 1, ferritin levels remained stable compared to baseline. At visit 2 and visit 3, a significant decrease in ferritin levels compared to baseline was observed ( $p<0.001$ for both visits). The decrease in ferritin levels at visit 3 was statistically not significant compared to visit $2(p=0.501)$.

\section{Estradiol}

Results demonstrate a significant increase in $17-\beta$ estradiol at visit 1 and visit 2 compared to baseline $(p<0.05$ for both visits). At visit 3, estradiol levels were not significantly different from baseline, but increased by trend (Table 1).

\section{Glycemic Control}

Mean HbA1c significantly decreased over the whole followup period compared to baseline ( $p<0.001$ at visit 1 and visit 2 , $p<0.05$ at visit 3). A gradual re-increase occurred at long-term follow-up, which was not statistically significant compared to visit 2 ( $p=0.057)$.

Accordingly, the percentage of patients with T2D decreased from 30.7 to $22.5 \%$ at visit $1(p<0.001), 10.2 \%$ at visit $2(p<0.001)$, and $6.7 \%$ at visit $3(p<0.001)$. Thirty percent of patients achieved complete remission of T2D.

\section{Subgroup Analysis}

\section{Inflammatory Parameters and Estradiol Levels in Men and Women}

Leucocytes, CRP, and hs-CRP significantly dropped over the whole follow-up period in male and female patients $(p<0.05)$. In both sexes, a significant decrease was observed in ferritin levels at visit 2 and visit 3 , but not in the short-term (visit 1 ). At baseline $(p<0.001)$, visit $1(p<0.001)$, and visit $2(p<0.05)$, ferritin levels in male patients were significantly higher than in female patients. In female patients, an increase in 17- $\beta$ estradiol by trend was observed, which was statistically significant at visit $2(p<0.05)$. In male patients, a slight, but not significant, decrease in 17- $\beta$ estradiol by trend was detected (Fig. 1).

\section{Inflammatory Parameters in Patients with SG vs. RYGB}

Comparing SG and RYGB, CRP levels were significantly higher at visit $2(p<0.05)$ in patients undergoing SG compared to RYGB. There were no significant differences in mean change from baseline of leucocyte count, CRP, and hs-CRP over the follow-up period between the surgical procedures. In the long-term, ferritin levels were significantly higher in patients undergoing SG compared to RYGB $(p<0.05)$.

\section{Inflammatory Parameters in Patients with T2D/Partial Remission Compared to Patients Without T2D/Complete Remission}

There was a strong, positive correlation between glycemic control and leucocyte levels at visit $1\left(r_{s}=0.16, p<0.05\right)$, hs$\mathrm{CRP}$ at visit $2\left(r_{s}=0.195, p<0.05\right)$, and visit $3\left(r_{s}=0.36\right.$, $p=0.001$ ), which was statistically significant (Table 2, Fig. 2). 
Table 1 Anthropometric and biochemical characteristics at baseline and follow-up visits

\begin{tabular}{|c|c|c|c|c|c|c|c|}
\hline Parameter & Baseline & Visit 1 & vs Baseline $(p)$ & Visit 2 & vs Baseline $(p)$ & Visit 3 & vs Baseline $(p)$ \\
\hline$N$ & 163 & 160 & & 128 & & 75 & \\
\hline Gender (F. $n)$ & 123 & 121 & & 100 & & 62 & \\
\hline Age (years) & $41.3 \pm 11.6$ & $42.2 \pm 11.6$ & & $44.4 \pm 11.5$ & & $45.6 \pm 10.6$ & \\
\hline Initial treatment SG $(n)$ & 108 & 106 & & 83 & & 45 & \\
\hline Initial treatment RYGB $(n)$ & 55 & 54 & & 45 & & 30 & \\
\hline Second step SG to RYGB $(n)$ & 4 & 4 & & 4 & & 4 & \\
\hline Second step SG to SADI $(n)$ & 2 & 1 & & 2 & & 1 & \\
\hline Time to treatment (months) & $-5.43 \pm 4.17$ & $5.32 \pm 1.44$ & & $23.56 \pm 3.94$ & & $44.67 \pm 5.88$ & \\
\hline Weight $(\mathrm{kg})$ & $153.5 \pm 29.2$ & $117.8 \pm 24.6$ & $<0.001$ & $104.0 \pm 26.1$ & $<0.001$ & $108.8 \pm 31.9$ & $<0.001$ \\
\hline BMI $\left(\mathrm{kg} / \mathrm{m}^{2}\right)$ & $51.63 \pm 8.02$ & $39.62 \pm 7.22$ & $<0.001$ & $35.20 \pm 7.99$ & $<0.001$ & $36.49 \pm 9.67$ & $<0.001$ \\
\hline EWL $(\%)$ & & $47.3 \pm 15.5$ & $<0.001$ & $63.8 \pm 23.5$ & $<0.001$ & $58.1 \pm 28.1$ & $<0.001$ \\
\hline Leucocytes $\left(10^{3} / \mu \mathrm{l}\right)$ & $9.3 \pm 2.3$ & $8.1 \pm 1.8$ & $<0.001$ & $7.8 \pm 2.0$ & $<0.001$ & $7.7 \pm 2.1$ & $<0.001$ \\
\hline CRP $(\mathrm{mg} / \mathrm{l})$ & $12.2 \pm 8.4$ & $7.5 \pm 4.6$ & $<0.001$ & $5.2 \pm 0.8$ & $<0.001$ & $5.5 \pm 1.8$ & $<0.001$ \\
\hline Hs-CRP (mg/dl) & $1.15 \pm 0.88$ & $0.58 \pm 0.53$ & $<0.001$ & $0.20 \pm 0.19$ & $<0.001$ & $0.25 \pm 0.30$ & $<0.001$ \\
\hline $\mathrm{Hb}(\mathrm{g} / \mathrm{dl})$ & $13.9 \pm 1.3$ & $13.6 \pm 1.2$ & 0.024 & $13.4 \pm 1.3$ & 0.002 & $13.0 \pm 1.7$ & $<0.001$ \\
\hline $\operatorname{Tf}(\mathrm{g} / \mathrm{l})$ & $2.9 \pm 0.5$ & $2.7 \pm 0.4$ & $<0.001$ & $2.8 \pm 0.5$ & 0.038 & $2.9 \pm 0.5$ & 0.673 \\
\hline Tf-Sat (\%) & $17.4 \pm 7.9$ & $18.8 \pm 9.3$ & 0.123 & $21.0 \pm 9.1$ & $<0.001$ & $17.2 \pm 10.5$ & 0.925 \\
\hline Ferritin $(\mu \mathrm{g} / \mathrm{l})$ & $104.5 \pm 93.5$ & $105.8 \pm 102.4$ & 0.904 & $67.7 \pm 82.3$ & $<0.001$ & $59.3 \pm 89.8$ & $<0.001$ \\
\hline Estradiol-17beta (ng/dl) & $53.8 \pm 47.9$ & $68.4 \pm 75.9$ & 0.040 & $83.8 \pm 105.2$ & 0.003 & $70.5 \pm 97.9$ & 0.165 \\
\hline AST (U/l) & $25.0 \pm 14.8$ & $21.4 \pm 9.1$ & 0.008 & $18.8 \pm 6.7$ & $<0.001$ & $19.8 \pm 6.0$ & $<0.001$ \\
\hline $\operatorname{ALT}(\mathrm{U} / \mathrm{L})$ & $39.1 \pm 26.2$ & $25.9 \pm 16.5$ & $<0.001$ & $25.3 \pm 9.1$ & $<0.001$ & $27.2 \pm 10.9$ & $<0.001$ \\
\hline GGT (U/l) & $46.1 \pm 59.2$ & $26.8 \pm 24.2$ & $<0.001$ & $24.3 \pm 14.3$ & $<0.001$ & $25.7 \pm 17.5$ & $<0.001$ \\
\hline Triglycerides (mg/dl) & $228.1 \pm 165.3$ & $153.4 \pm 75.1$ & $<0.001$ & $153.1 \pm 124.3$ & $<0.001$ & $140.5 \pm 94.6$ & $<0.001$ \\
\hline HDL-Cholesterol (mg/dl) & $45.9 \pm 13.7$ & $47.8 \pm 11.8$ & 0.186 & $62.1 \pm 15.9$ & $<0.001$ & $59.1 \pm 15.8$ & $<0.001$ \\
\hline LDL-Cholesterol (mg/dl) & $104.2 \pm 32.9$ & $103.5 \pm 29.3$ & 0.864 & $96.9 \pm 30.9$ & 0.063 & $104.6 \pm 29.9$ & 0.916 \\
\hline HbA1c $(\%)$ & $5.86 \pm 1.09$ & $5.35 \pm 0.71$ & $<0.001$ & $5.37 \pm 0.76$ & $<0.001$ & $5.59 \pm 0.83$ & 0.036 \\
\hline $\mathrm{HbA} 1 \mathrm{c}<6.5 \%(\%)$ & $5.51 \pm 0.44$ & $5.22 \pm 0.36$ & $<0.001$ & $5.21 \pm 0.34$ & $<0.001$ & $5.42 \pm 0.35$ & 0.146 \\
\hline $\mathrm{HbA} 1 \mathrm{c} \geq 6.5 \%(\%)$ & $7.75 \pm 1.52$ & $7.74 \pm 1.26$ & 0.988 & $7.53 \pm 1.37$ & 0.370 & $7.94 \pm 1.83$ & 0.802 \\
\hline
\end{tabular}

Data are reported as means \pm SD. $N$, number of individuals; $S G$, sleeve gastrectomy; $R Y G B$, Roux-en-Y gastric bypass; $S A D I$, single anastomosis duodeno-ileal bypass; $B M I$, body mass index; $E W L$, excess weight loss; $C R P, \mathrm{C}$-reactive protein; $H s$ - $C R P$, high-sensitive $\mathrm{C}$-reactive protein; $H b$, hemoglobin; Tf, transferrin; Tf-Sat, transferrin saturation; $A S T$, aspartate transaminase; $A L T$, alanine-aminotransferase; $G G T$, gamma-glutamyl transferase; $H D L$, high-density lipoprotein; $L D L$, low-density lipoprotein

\section{Univariate Regression Analysis for Long-Term Change in Inflammatory Parameters}

Change in BMI at long-term follow-up showed a significant linear effect on change in leucocytes $(B=0.082$; $p<0.001)$ and change in hs-CRP $(B=0.03 ; p<0.05)$. Results of univariate regression analysis are shown in Table 3. Patients with optimal weight loss showed a significant drop of leucocytes, CRP, and hs-CRP over the whole follow-up period $(p<0.001)$. In patients with suboptimal weight loss, there was no significant decrease in leucocytes at long-term. In both subgroups, ferritin levels significantly decreased in patients with optimal $(p<0.001)$ and suboptimal weight loss $(p<0.05)$ in the long-term.

\section{Conclusion}

Results of the present study provide important data on the long-term effects of BS on inflammatory markers. Since long-lasting inflammation in obesity is discussed as one of the main factors contributing to severe complications of viral infections, e.g., SARS-CoV-2, surgery-induced long-term changes in chronic low-grade inflammation are of particular clinical relevance [16].

In the present study cohort, a decline in CRP, hs-CRP, and leucocyte count was observed according to the U-shaped curve of weight loss with the lowest level of inflammation 2 years after BS followed by a gradual increase 4 years after BS. Assumingly, as a consequence of a gradual re-increase of food 


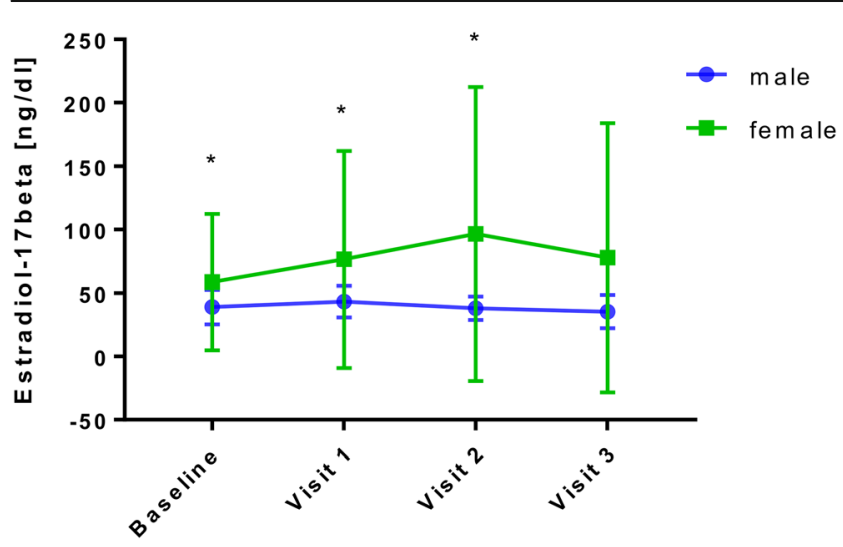

Fig. 1 Baseline concentrations and postoperative course of 17ß-estradiol of male and female patients underwent bariatric surgery (BS). Baseline, before BS; visit 1, 6 months after BS; visit 2, 2 years after BS; visit 3, 4 years after BS. Data are presented as means \pm SD. $* p<0.05$

intake and body weight, metabolic parameters like LDL-cholesterol, liver enzymes, and HbAlc displayed the same Ushaped curve. However, 4 years following BS, complete normalization of hs-CRP occurred in $84.0 \%$ of patients.

Moreover, the change in inflammatory parameters was related to the degree of weight loss. The most pronounced decline in inflammatory parameters was observed during the first 6 months following BS. Previous studies have observed similar short-term results [17-19]. At long-term follow-up, change in BMI showed a significant linear effect on change in leucocytes and change in hs-CRP. Patients with suboptimal weight loss showed increased leucocytes and hs-CRP levels in the long term. A recent study using latent class trajectory analysis demonstrated that steeper weight gain trajectories were associated with elevated risk of inflammation compared to more moderate weight gain trajectories, even after adjustment for initial weight, over a period of 18 years [20]. Analogously, our results clearly demonstrate that steeper weight loss was associated with decreased risk of inflammation in the long-term.

However, comparing SG and RYGB, there were no significant differences in the decline of CRP, hs-CRP, and leucocytes, even though EWL was significantly higher in patients undergoing RYGB 2 and 4 years post BS compared to SG. These data are in line with previous studies with a study duration up to 12 months $[10,21]$. In contrast, a significant effect of type of surgery on CRP levels except the biliopancreatic diversion (BPD) was found according to a systematic review including studies with a study duration up to 24 months [11]. The lack of difference in our cohort might be explained by the fact that change in BMI, which must be considered the main driver for change in inflammatory parameters, was not significantly different in the long term between SG and RYGB. Moreover, the homogeneity of metabolic control between groups may play a crucial role. There were no significant differences in $\mathrm{HbA} 1 \mathrm{c}$ in the long term, and $\mathrm{HbAlc}$ was only within the prediabetic range in both subgroups. Given the superiority of RYGB over SG in patients with obesity and T2D [22], it can be speculated that in a more metabolically unhealthy cohort, patients undergoing RYGB would have experienced a more pronounced decline in inflammatory parameters.

Patients with T2D showed increased inflammatory markers in the long-term (leucocytes and hs-CRP) compared to patients without T2D. In our cohort, 30.0\% of patients achieved complete remission of T2D in the long term, whose profile was almost identical to those without T2D. Even though similar short-term results have been found showing that CRP showed a positive correlation with $\mathrm{HbA} 1 \mathrm{c} \geq 6.5 \%$ [10], long-term results are of particular pathophysiological interest. T2D is known as a proinflammatory state with increased levels of hs-CRP and proatherogenic activity, which promotes increased micro- and macrovascular complications [23]. Data from 11 randomized controlled trials investigating clinical outcomes of metabolic surgery were not powered sufficiently to detect differences in micro- or macrovascular events, especially at relatively short follow-up [24]. However, our data highlight the clinical relevance of metabolic surgery, which can reverse and improve T2D, and therefore might prevent or slow atherogenesis in the long-term by breaking the vicious circle between inflammation and endothelial dysfunction [25].
Table 2 Spearman's rank correlation between glycemic control and inflammatory parameters

\begin{tabular}{llll}
\hline Parameter & Visit 1 & Visit 2 & Visit 3 \\
\hline Leucocytes $\left(10^{3} / \mu \mathrm{l}\right)$ & $\mathbf{0 . 1 6 0}(\boldsymbol{p}=\mathbf{0 . 0 4 3})$ & $0.119(p=0.181)$ & $0.179(p=0.123)$ \\
CRP $(\mathrm{mg} / \mathrm{l})$ & $0.026(p=0.742)$ & $0.031(p=0.731)$ & $0.019(p=0.868)$ \\
Hs-CRP $(\mathrm{mg} / \mathrm{dl})$ & $0.060(p=0.454)$ & $\mathbf{0 . 1 9 5}(p=\mathbf{0 . 0 2 7})$ & $\mathbf{0 . 3 6 4}(\boldsymbol{p}=\mathbf{0 . 0 0 1})$ \\
Ferritin $(\mu \mathrm{g} / \mathrm{l})$ & $0.063(p=0.429)$ & $0.070(p=0.430)$ & $0.096(p=0.412)$ \\
Estradiol-17beta $(\mathrm{ng} / \mathrm{dl})$ & $0.089(p=0.264)$ & $0.100(p=0.259)$ & $0.004(p=0.970)$ \\
\hline
\end{tabular}

$C R P, \mathrm{C}$-reactive protein; $H s$ - $C R P$, high-sensitive $\mathrm{C}$-reactive protein 


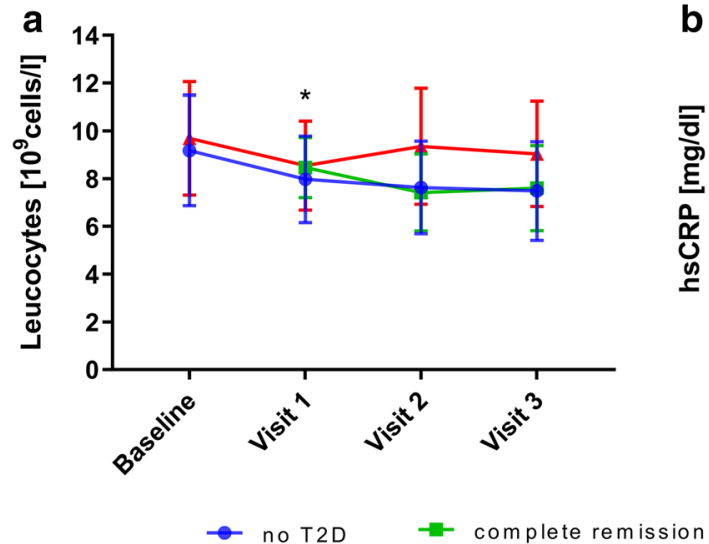

Fig. 2 Baseline and postoperative course of leucocytes (A) and highsensitive C-reactive protein (hs-CRP levels) (B) for patients without type 2 diabetes mellitus (T2D), complete remission of T2D and patients with $\mathrm{T} 2 \mathrm{D} /$ partial remission. Hs-CRP, high-sensitive C-reactive protein. T2D,

There were no significant long-term differences in the decline of CRP, hs-CRP, and leucocytes between male and female patients. Different short-term results were found by Chiapetta et al. in a similar cohort, who observed a significant change in CRP only in female patients referring to the antiinflammatory effects of endogenous estrogen $[10,26]$. Weight loss restores gonadal dysfunction in men and women as soon as 6 months after surgery [27, 28], studies focusing on the long-term duration of restored gonadal function are lacking though. In female patients of our cohort, 17ß-estradiol levels increased by trend, but did not change significantly in the long term. In male patients, 17ß-estradiol decreased by trend, but there were no significant changes as typically seen following weight loss in male-obesity secondary hypogonadism [29, 30]. It can be assumed that more pronounced hormonal alterations after adjusting for age, gender, and BMI would have confirmed the anti-inflammatory properties of 17ß-estradiol [5]. Data from 6916 patients with severe obesity diagnosed with COVID-19 showed that mortality was most striking

Table 3 Univariate regression analysis between change in BMI and change in inflammatory parameters at visit 3

\begin{tabular}{lllll}
\hline Dependent parameter & \multicolumn{1}{l}{$\mathrm{B}$} & $\mathrm{SE}(\mathrm{B})$ & \multicolumn{1}{l}{$l$} & $R^{2}$ \\
\hline$\Delta$ Leucocytes $\left(10^{3} / \mu \mathrm{l}\right)$ & 0.082 & 0.023 & $<0.001$ & 0.145 \\
$\Delta$ CRP $(\mathrm{mg} / \mathrm{l})$ & 0.192 & 0.103 & 0.065 & 0.046 \\
$\Delta$ hs-CRP $(\mathrm{mg} / \mathrm{dl})$ & 0.030 & 0.011 & 0.005 & 0.101 \\
$\Delta$ Ferritin $(\mu \mathrm{g} / \mathrm{l})$ & 0.204 & 0.842 & 0.809 & 0.001 \\
$\Delta$ Estradiol-17beta (ng/dl) & -2.079 & 1.471 & 0.162 & 0.027 \\
\hline
\end{tabular}

$C R P$, C-reactive protein; $H s-C R P$, high-sensitive C-reactive protein; $B$ regression coefficient. $R^{2}$, R squared; $S E$, standard error; $C R P, \mathrm{C}$-reactive protein; $H_{s}-C R P$, high-sensitive $\mathrm{C}$-reactive protein

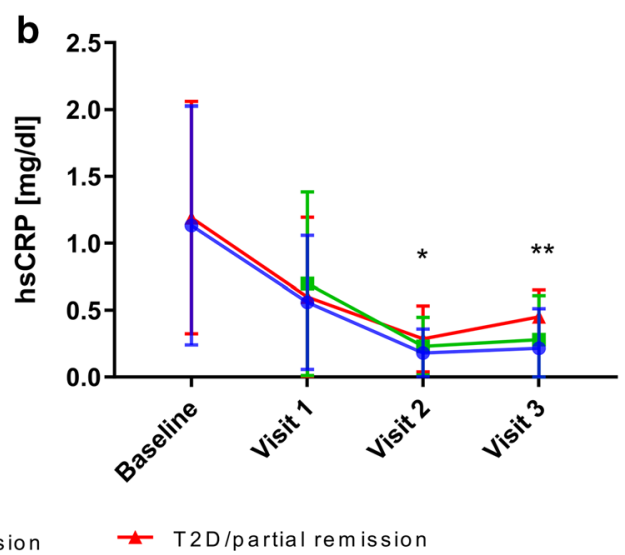

type 2 diabetes. Baseline, before BS; visit 1, 6 months after BS; visit 2, 2 years after BS; visit 3, 4 years after BS. Data are presented as means \pm SD. ${ }^{*} p<0.05, * * p<0.001$, spearman's rank correlation between hs-CRP/ leucocytes and manifestation of T2DM

among men [31]. Therefore, studies addressing the impact of surgery-induced weight loss on sex hormone levels and inflammatory disease susceptibility are urgently needed.

Interestingly, results of the present study observed significantly increased ferritin levels in male patients at baseline and within 2 years of surgery, which may be explained by the higher BMI at baseline and throughout the study period that may lead to hyperferritinemia irrespective of body iron stores [32]. Moreover, the percentage of male patients with T2D (45\%) was significantly higher compared to female patients (26\%) which is a condition frequently associated with elevated levels of serum ferritin [33].

In conclusion, results of the present study clearly reveal a profound improvement in chronic inflammation up to 4 years following BS irrespective of type of surgery and gender. Close follow-up should be provided for patients to prevent gradual weight gain and associated worsening of inflammatory parameters in the long term.

Acknowledgements Ina Bähr and Jens Aberle contributed equally to this work.

Funding Open Access funding enabled and organized by Projekt DEAL.

\section{Declarations}

Ethical Approval For this type of study formal consent is not required.

Informed Consent Informed consent does not apply.

Conflict of Interest The authors declare no competing interests.

Tobias B. Huber reports grants and personal fees from Fresenius Medical Care / Unicyte, grants from Amicus Therapeutics, grants from Genzyme / Sanofi, personal fees from Boehringer Ingelheim, personal 
fees from Goldfinch Bio, personal fees from Novartis Pharma GmbH, personal fees from DaVita Deutschland AG, personal fees from Bayer Vital $\mathrm{GmbH}$, outside the submitted work.

Open Access This article is licensed under a Creative Commons Attribution 4.0 International License, which permits use, sharing, adaptation, distribution and reproduction in any medium or format, as long as you give appropriate credit to the original author(s) and the source, provide a link to the Creative Commons licence, and indicate if changes were made. The images or other third party material in this article are included in the article's Creative Commons licence, unless indicated otherwise in a credit line to the material. If material is not included in the article's Creative Commons licence and your intended use is not permitted by statutory regulation or exceeds the permitted use, you will need to obtain permission directly from the copyright holder. To view a copy of this licence, visit http://creativecommons.org/licenses/by/4.0/.

\section{References}

1. Mraz M, Haluzik M. The role of adipose tissue immune cells in obesity and low-grade inflammation. J Endocrinol. 2014;222(3): R113-27. https://doi.org/10.1530/JOE-14-0283.

2. Hotamisligil GS. Inflammation and metabolic disorders. Nature. 2006;444(7121):860-7. https://doi.org/10.1038/nature05485.

3. Merhi ZO, Durkin HG, Feldman J, et al. Effect of bariatric surgery on peripheral blood lymphocyte subsets in women. Surg Obes Relat Dis. 2009;5:165-71.

4. Reddy P, Lent-Schochet D, Ramakrishnan N, et al. Metabolic syndrome is an inflammatory disorder: a conspiracy between adipose tissue and phagocytes. Clin Chim Acta. 2019;496:35-44. https:// doi.org/10.1016/j.cca.2019.06.019.

5. Miller CN, Brown LM, Rayalam S, et al. Estrogens, inflammation and obesity: an overview [Internet]. Front Biol. 2012;7:40-7. https://doi.org/10.1007/s11515-011-1174-y.

6. Zhu C, Gao J, Mei F, et al. Reduction in thyroid-stimulating hormone correlated with improved inflammation markers in Chinese patients with morbid obesity undergoing laparoscopic sleeve gastrectomy. Obes Surg Springer. 2019;29:3954-65.

7. Dixon JB, O'Brien PE. Obesity and the white blood cell count: changes with sustained weight loss. Obes Surg. 2006;16:251-7.

8. Salman MA, Salman AA, Nafea MA, et al. Study of changes of obesity-related inflammatory cytokines after laparoscopic sleeve gastrectomy. ANZ J Surg. Blackwell Publishing. 2019;89:1265-9.

9. Hagman DK, Larson I, Kuzma JN, et al. The short-term and longterm effects of bariatric/metabolic surgery on subcutaneous adipose tissue inflammation in humans. Metabolism. W.B. Saunders. 2017;70:12-22.

10. Chiappetta S, Schaack HM, Wölnerhannsen B, et al. The impact of obesity and metabolic surgery on chronic inflammation. Obes Surg. Springer New York LLC. 2018;28:3028-40.

11. Askarpour M, Khani D, Sheikhi A, et al. Effect of bariatric surgery on serum inflammatory factors of obese patients: a systematic review and meta-analysis. Obes Surg. 2019;29(8):2631-47. https:// doi.org/10.1007/s11695-019-03926-0.

12. Zusammenarbeit I (2010) Chirurgische Arbeitsgemeinschaft für Adipositastherapie (CA-ADIP) Deutsche Adipositas-Gesellschaft (DAG) Deutsche Gesellschaft für Psychosomatische Medizin und Psychotherapie Deutsche Gesellschaft für Ernährungsmedizin S3Leitlinie: Chirurgie der Adipositas [Internet]. Available from: www.adipositas-gesellschaft.de
13. Cadena-Obando D, Ramírez-Rentería C, Ferreira-Hermosillo A, et al. Are there really any predictive factors for a successful weight loss after bariatric surgery? BMC Endocr Disord. 2020;20(1):20. https://doi.org/10.1186/s12902-020-0499-4.

14. Magro DO, Geloneze B, Delfini R, et al. Long-term weight regain after gastric bypass: a 5 -year prospective study. Obes Surg. 2008;18:648-51.

15. Isaman DJM, Rothberg AE, Herman WH (2016) Reconciliation of type 2 diabetes remission rates in studies of Roux-en-Y gastric bypass. Diabetes Care. American Diabetes Association Inc.; 39: 2247-53

16. Popkin BM, Du S, Green WD, et al. Individuals with obesity and COVID-19: a global perspective on the epidemiology and biological relationships. Obes Rev. 2020;21(11):e13128. https://doi.org/ 10.1111/obr.13128.

17. Netto BDM, Bettini SC, Clemente APG, et al. Roux-en-Y gastric bypass decreases pro-inflammatory and thrombotic biomarkers in individuals with extreme obesity. Obes Surg. Springer New York LLC. 2015;25:1010-8.

18. Afshar S, Malcomson F, Kelly SB, et al. Biomarkers of colorectal cancer risk decrease 6 months after Roux-en-Y gastric bypass surgery. Obes Surg. Springer New York LLC. 2018;28:945-54.

19. Illán-Gómez F, Gonzálvez-Ortega M, Orea-Soler I, et al. Obesity and inflammation: change in adiponectin, $\mathrm{C}$-reactive protein, tumour necrosis factor-alpha and interleukin- 6 after bariatric surgery. Obes Surg. 2012;22:950-5.

20. Thompson AL, Koehler E, Herring AH, et al. Weight gain trajectories associated with elevated C-reactive protein levels in Chinese adults. J Am Heart Assoc. 2016;5(9):e003262. https://doi.org/10. 1161/JAHA.116.003262.

21. Fenske WK, Dubb S, Bueter M, et al. Effect of bariatric surgeryinduced weight loss on renal and systemic inflammation and blood pressure: A 12-month prospective study. Surg Obes Relat Dis. 2013;9:559-68.

22. McTigue KM, Wellman R, Nauman E, et al. Comparing the 5-year diabetes outcomes of sleeve gastrectomy and gastric bypass the national patient-centered clinical research network (PCORNet) bariatric study. JAMA Surg. 2020;155(5):e200087. https://doi.org/10. 1001/jamasurg.2020.0087.

23. Devaraj S, Dasu MR, Jialal I. Diabetes is a proinflammatory state: a translational perspective. Expert Rev Endocrinol Metab. 2010;5(1): 19-28. https://doi.org/10.1586/eem.09.44.

24. Schauer PR, Mingrone G, Ikramuddin S, et al. Clinical outcomes of metabolic surgery: efficacy of glycemic control, weight loss, and remission of diabetes metabolic surgery. Diabetes Care. 2016;39: 902-11.

25. Carmona-Maurici J, Cuello E, Ricart-Jané D, et al. Effect of bariatric surgery on inflammation and endothelial dysfunction as processes underlying subclinical atherosclerosis in morbid obesity. Surg Obes Relat Dis Elsevier Inc. 2020;16:1961-70.

26. Kassi E, Spilioti E, Nasiri-Ansari N, et al. Vascular inflammation and atherosclerosis: the role of estrogen receptors. Curr Med Chem. Bentham Science Publishers Ltd. 2015;22:2651-65.

27. Casimiro I, Sam S, Brady MJ. Endocrine implications of bariatric surgery: a review on the intersection between incretins, bone, and sex hormones. Physiol Rep. 2019;7(10):e14111. https://doi.org/10. 14814/phy2.14111.

28. Escobar-Morreale HF, Santacruz E, Luque-Ramírez M, et al. Prevalence of "obesity-associated gonadal dysfunction" in severely obese men and women and its resolution after bariatric surgery: a systematic review and meta-analysis. Hum Reprod Update. Oxford University Press. 2017;23:390-408. 
29. Hammoud A, Gibson M, Hunt SC, et al. Effect of Roux-en-Y gastric bypass surgery on the sex steroids and quality of life in obese men. J Clin Endocrinol Metab [Internet]. Endocrine Society. 2009;94:1329-32. [cited 2021 Feb 14];Available from: http://www.ncbi.nlm.nih.gov/pubmed/19174499

30. de Lorenzo A, Noce A, Moriconi E, et al. MOSH syndrome (male obesity secondary hypogonadism): clinical assessment and possible therapeutic approaches. Nutrients. 2018;10(4):474. https://doi.org/ 10.3390/nu10040474.

31. Tartof SY, Qian L, Hong V, et al. Obesity and mortality among patients diagnosed with COVID-19: results from an integrated health care organization. Ann Intern Med. NLM (Medline). 2020;173:773-81.
32. Alam F, Memon AS, Fatima SS. Increased body mass index may lead to hyperferritinemia irrespective of body iron stores. Pakistan J Med Sci [Internet]. Professional Medical Publications. 2015;31: 1521-6. cited 2021 Feb 14];Available from: http://www.ncbi.nlm. nih.gov/pubmed/26870128

33. Lecube A, Hernández $\mathrm{C}$, Genescà $\mathrm{J}$, et al. Diabetes is the main factor accounting for the high ferritin levels detected in chronic hepatitis C virus infection. Diabetes Care. 2004;27:2669-75.

Publisher's Note Springer Nature remains neutral with regard to jurisdictional claims in published maps and institutional affiliations. 